1 Faculty of Psychiatry of Intellectual Disability, Royal College of Psychiatrists, London, UK

2 The Challenging Behaviour Foundation, Kent, UK

Correspondence to: K Courtenay ChairFacultyPID@rcpsych.ac.uk Cite this as: BMJ 2021;374:n1701 http://dx.doi.org/10.1136/bmj.n1701

Published: 15 July 2021

\section{Covid 19: People with learning disabilities are highly vulnerable}

\author{
They must be prioritised, and protected \\ Ken Courtenay, ${ }^{1}$ Vivien Cooper ${ }^{2}$
}

The covid-19 pandemic has had a devastating effect on people with learning disabilities across the world. The linked paper by the OpenSAFELY collaborative led by Williamson and colleagues

(doi:10.1136/bmj.n1592) makes an important contribution to the evidence on how the pandemic has affected this vulnerable group. ${ }^{1}$ The findings that people with learning disabilities with covid-19 were five times more likely to be admitted to hospital and eight times more likely to die supports the findings of other studies. ${ }^{2-4}$ People with learning disabilities are extremely vulnerable to the effects of SARS-CoV-2 infection.

The NHS Long Term Plan in 2019 acknowledged the inequalities and prioritised annual health checks and influenza vaccination (through targets in primary care in England) to help reduce morbidity. ${ }^{5}$ Before the pandemic, clinicians in learning disability services and families were well aware of the high prevalence of comorbid disorders ${ }^{6}$ and unacceptably high mortality rates ${ }^{7}$ affecting people with learning disabilities. On average, people with learning disabilities die more than 20 years younger than the general population. ${ }^{8}$

With the arrival of covid-19, families and specialist services knew people with learning disabilities were particularly vulnerable but were uncertain how to protect them. While the focus was on older adults, whose mortality rates shocked the nation, a hidden calamity was also taking place among people with learning disabilities. Data from Public Health England in 2020 show that mortality rates in this group were up to three times higher than that of the general population. ${ }^{4}$

People with learning disabilities often need care from a young age and might require lifelong support. The services that support this diverse group with a range of health and care needs are also varied. People with learning disabilities might live in community settings (in supported living arrangements or residential care) or live with their families with support. Some people share accommodation, and support workers or personal assistants might work across settings with several different individuals.

In line with their human rights and with government policy, individuals with learning disabilities should enjoy and participate in the same activities as all citizens. Reasonable adjustments should be made to ensure that information about the pandemic and risk of infection are accessible, and that practical support is provided to protect people and manage risks.

\section{Prejudice}

Worrying attitudes and prejudices about the value of the lives of people with learning disabilities have surfaced during the pandemic. Use of DNACPR (Do Not Attempt Cardiopulmonary Resuscitation) orders for people with life threatening infections resulted in fear and outrage among the families of people with learning disabilities, friends, advocates, and those providing support. ${ }^{9}$ The clear implication was that the value of a person's life would be based on age and degree of cognitive impairment, returning to a time when disability was openly stigmatised.

Self-advocates and families campaigned strenuously to overturn blanket decisions that were not based on an individual's best interests.

The covid-19 vaccination programme also disadvantaged people with learning disabilities, prioritising people according to age rather than severity of comorbid disorders. ${ }^{10} \mathrm{BBC}$ presenter Jo Wiley for example, reported how she and her parents were offered vaccines before her sister, who had a severe learning disability. ${ }^{11} 12$

Initially, young people with other high risk conditions were more likely to be offered vaccination than peers of the same age with learning disabilities, and this was only overturned after calls from self-advocates and families.

We must work much harder to reduce the health inequalities exposed and amplified by the pandemic-including further training of all health and care staff about the needs of people with learning disabilities and the health inequalities they face.

Mechanisms already in place also need to work more effectively and efficiently. The new OpenSAFELY study highlights that learning disability registers in general practice are incomplete, limiting the reach of the vaccination programme. Greater efforts to update and maintain accurate registers are required so that all eligible individuals can benefit.

The specialist role of learning disability doctors should be developed to provide holistic, specialised, and tailored healthcare and support to people with learning disabilities in both primary and secondary healthcare settings ${ }^{13}$. In addition to direct care, specialist clinicians would provide support, expertise, and guidance to other healthcare professionals to improve the care of people with learning disabilities across all services in the NHS.

Before the next pandemic, investment in research is essential, to help us understand the risks faced by people with learning disabilities and how best to protect them from the high risks of hospital admission and death from covid-19 identified by Williamson and colleagues. People with learning disabilities have the same rights as everyone else, including the right to good health and to be safe from harm. 
Competing interests: The BMJ has judged that there are no disqualifying financial ties to commercial companies. The authors declare the following other interests: None

Provenance and peer review: Commissioned; not peer reviewed.

1 Williamson EJ, McDonald HI, Bhaskaran K, etal. Risks of covid-19 hospital admission and death for people with learning disability: population based cohort study using the OpenSAFELY platform. BMJ 2021;374:n1592.

2 Watkins A. COVID-19-Related Deaths in Wales amongst People with Learning Disabilities from 1st March to 26th May 2020. Improvement Cymru; 2020. Accessed March 3, 2020.

https:/phw.nhs.wales/publications/publications1/covid-19-related-deaths-in-wales-amongst-people-with-leaming-disabilities/

3 Landes SD, Turk MA, Formica MK, McDonald KE, Stevens JD. COVID-19 outcomes among people with intellectual and developmental disability living in residential group homes in New York State. Disabil Health J2020;13:100969. doi: 10.1016/j.dhjo.2020.100969. pmid: 32600948

4 Public Health England. COVID-10: deaths of people with learning disabilities. Published November 12, 2020. https://www.gov.uk/government/publications/covid-19-deaths-of-people-with-learningdisabilities

5 NHS. The NHS long term plan. 2019. https://www.longtermplan.nhs.uk/

6 Kinnear D, Morrison J, Allan L, Henderson A, Smiley E, Cooper SA. Prevalence of physical conditions and multimorbidity in a cohort of adults with intellectual disabilities with and without Down syndrome: cross-sectional study. BMJ Open 2018:8:e018292.

doi: 10.1136/bmjopen-2017-018292 pmid: 29431619

7 Heslop P, Calkin R, Byrne V. The Learning Disabilities Mortality Review (LeDeR) Programme: Annual Report 2019. University of Bristol, Norah Fry Centre for Disability Studies, 2020.

8 Glover G, Williams R, Heslop P, Oyinlola J, Grey J. Mortality in people with intellectual disabilities in England. J Intellect Disabil Res 2017;61:62-74. doi: 10.1111/jir.12314 pmid: 27489075

9 Care Quality Commission. Protect, respect, connect-decisions about living and dying well during COVID-19. 18 Mar 2021. https://www.cqc.org.uk/publications/themed-work/protect-respectconnect-\%E2\%80\%93-decisions-about-living-dying-well-during-covid-19.

10 Department of Health and Social Care. Joint Committee on Vaccination and Immunisation: advice on priority groups for covid-19 vaccination. 30 December 2020. https://assets.publishing.service.gov.uk/government/uploads/system/uploads/attachment_data/file/950113/jcvi-advice-onpriority-groups-for-covid-19-vaccination-30-dec-2020-revised.pdf.

11 BBC News. Jo Whiley: It's been the worst week of our lives as Frances struggles with Covid. 21 February 2021. https://www.bbc.co.uk/news/uk-56139393

12 Department of Health and Social Care. JCVI advises inviting people on Learning Disability Registe for vaccine. 24 February 2021 www.gov.uk/government/news/jcvi-advises-inviting-people-onlearning-disability-register-for-vaccine.

13 Courtenay K. A case for learning disability doctors. The Guardian 26 July 2019. https://www.theguardian.com/society/2019/jul/26/a-case-for-learning-disability-doctors

This article is made freely available for use in accordance with BMJ's website terms and conditions for the duration of the covid-19 pandemic or until otherwise determined by BMJ. You may use, download and print the article for any lawful, non-commercial purpose (including text and data mining) provided that all copyright notices and trade marks are retained. 